\title{
An Early Portuguese Contribution to Air Navigation
}

\author{
Charles H. Cotter
}

A RECENT Portuguese postage stamp of interest to philatelists and navigators alike was issued to commemorate the fiftieth anniversary of an adventurous air flight over the Atlantic from Portugal to Brazil by two officers of the Portuguese Navy, Rear-Admiral Cago Coutinho and Commander Sacadura Cabral.1

In a valuable memoir published in English as well as in Portuguese by the Club Militar Naval of Lisbon an account of the novel method of navigation adopted by the two aviators is given. In the foreword to the memoir we are told:

'The use of points of reference through the line of the intended crossing, and the able and skilful modifications of the formulae of nautical astronomy, by which the observer may, before starting, prepare the greater part of his calculations, in this way leaving only another quite material [small] part to be done in the air, are the two original conceptions by which the astronomical navigation, with a sextant, can be done in the air with accuracy and comfort . . '

From this it is seen that a matter which received attention was the selection of suitable points of reference, at equal or nearly equal distances apart along the line of the proposed route. These points were separated by $2^{\circ}$. of latitude and $I^{\circ}$ of longitude. Near the equator for example the points chosen were:

\begin{tabular}{c|c|l}
\hline Point & Lat. & Long. \\
\hline A & $14^{\circ} \mathrm{N}$. & $24^{\circ} \mathrm{W}$. \\
B & $12^{\circ} \mathrm{N}$. & $25^{\circ} \mathrm{W}$. \\
C & $10^{\circ} \mathrm{N}$. & $26^{\circ} \mathrm{W}$. \\
& & \&c. \\
\hline
\end{tabular}

In an aircraft flying at a relatively high speed (but not at the time more than that of an express train) it was possible to determine with some degree of accuracy the time at which each point would be reached, so that the astronomical ephemeral data for the Sun (or any other celestial body suitable for navigation) could be worked out beforehand. Such preparations having been made in advance the next step was, by suitable manipulation of the sight-reduction formula, to obtain an expression which permitted as much as possible of the computing work to be done in advance. The process adopted by the Portuguese navigators was based on the Marcq Saint Hilaire method and they derived an interesting formula from the fundamental cosine rule, as follows: 
For any PZX triangle:

$$
\begin{aligned}
\cos \mathrm{ZX} & =\cos \mathrm{P} \sin \mathrm{PZ} \sin \mathrm{PX}+\cos \mathrm{PZ} \cos \mathrm{PX} \\
& =\sin \mathrm{PZ} \sin \mathrm{PX} / \sec \mathrm{P}+\cos \mathrm{PZ} \cos \mathrm{PX} \\
& =\sin \mathrm{PZ} \sin \mathrm{PX} / \sec \mathrm{P}+\cos \mathrm{PZ} \cos \mathrm{PX} \sec \mathrm{P} / \sec \mathrm{P} \\
& =\cos \mathrm{PZ} \cos \mathrm{PX}(\mathrm{I}+\tan \mathrm{PZ} \tan \mathrm{PX} / \sec \mathrm{P}) \\
\sin a & =\sin 1 \sin d(\mathrm{I} \pm \cot 1 \cot d / \sec \mathrm{P}) \\
& =S(\mathrm{I} \pm C / \sec \mathrm{P})
\end{aligned}
$$

where $S=(\sin l \sin d) ; C=(\cot l \cot d)$; and $l$ and $d$ denote respectively latitude of observer and declination of the observed body.

The quantities $S$ and $C$ can be pre-computed for each point of reference, thus leaving only the hour angle $P$ to be found for the time of the observation.

To solve the equation for altitude recourse was made to Houël's Tables ${ }^{2}$ which include gaussian logarithms, 3 by means of which one is able to extract the logarithm of a quantity increased or decreased by unity, and in particular the logarithms of $(\mathrm{I}+C / \sec \mathrm{P})$ or $(\mathrm{I}-C / \sec \mathrm{P})$.

The formula used by Coutinho and Cabral has general application, but for navigating in the tropical zone they used an even shorter method for finding zenith distance. The following extract from the memoir mentioned above serves to explain the method they devised :

'In the neighbourhood of the equator, and when the Sun has a low declination ... the altitude of the Sun, which nears $90^{\circ}$ at noon, does not differ much from its hour angle. And, as the variation of the sum of the hour angle and the altitude is slow, at least in the later hours, it becomes easy to compute a table for that sum. Therefore, starting from the hour angle, an altitude is immediately obtained by means of an interpolation at sight and an elementary subtraction. Such was our case when we approached Saint Paul's Rocks. The table used on that occasion, and also an example, will give a quick idea of the practical execution of the process ...'

The data for the example were: $1=1^{\circ} \mathrm{N} ., d=10^{\circ} 45^{\prime} \mathrm{N}$, , hour angle $\mathrm{P}=$ $4^{\mathrm{h}} 54^{\mathrm{m}} 45^{\mathrm{s}}$. True latitude $=16^{\circ} \circ 8^{\prime}$.

With given values of latitude and declination and successive values of hour angle, results were obtained as follows :

For $\mathrm{P}=4^{\mathrm{h}} 40^{\mathrm{m}}$, or $70^{\circ}$, the altitude (a) was found to be $19^{\circ} 49^{\prime}$, and the sum of $P$ and $a\left(70^{\circ}+19^{\circ} 49^{\prime}\right)=89^{\circ} 49^{\prime}$. Similarly for values of $P$ increasing in each case by $10^{\mathrm{m}}$ or $2^{\circ} 30^{\prime}$. The following is a section of the resulting table:

\begin{tabular}{c|r}
\hline$P$ & Sum \\
\hline $4^{\mathrm{n}} 40^{\mathrm{m}}$ & $89^{\circ} 49^{\prime}$ \\
$50^{\mathrm{m}}$ & $5^{\prime}$ \\
$5^{\mathrm{n}} 00^{\mathrm{m}}$ & $54^{\prime}$ \\
$10^{\mathrm{m}}$ & $57^{\prime}$ \\
$20^{\mathrm{m}}$ & $90^{\circ} 00^{\prime}$ \\
& \\
\hline
\end{tabular}

To find the altitude required, the observation having been made at $\mathrm{P}=$ $4^{\mathrm{b}} 54^{\mathrm{m}} 45^{\mathrm{s}}$, the work is completed in the air: 
From Table :

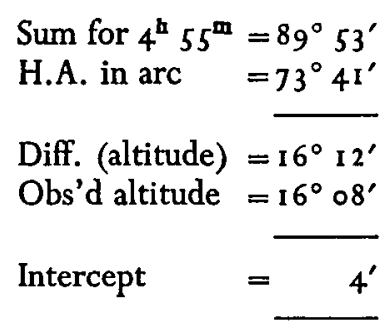

In his History of Air Navigation, 4 the late A. J. Hughes refers to the first non-stop South Atlantic flight made by Cabral and Coutinho.

'They had good weather and used the sea horizon for sextant observations, and specially prepared tables for reducing the observations. They claim to have known the exact position within four or five miles continuously on the flight, and picked up Saint Paul's Rocks, a mere speck in the sea . . . Coutinho was a great believer in the sextant, and after the flight invented a bubble sextant. . . . They made the flight $(4,367$ miles from Lisbon to Pernambuco) in 60 hours of flying time...'

H. B. Goodwin 5 described how the pre-computations necessary in the Coutinho method could be simplified by means of Frederick Ball's inspection Tables 6 and had every expectation that the Coutinho method would have universal popularity:

'The method', wrote Goodwin, 'seems calculated to be of much service, both in the navigation of the air, for which it was specially designed, and of the ocean also ...'

This was not to be so, and within a relatively short time after its first appearance the ingenious Coutinho method was all but forgotten; it is of interest to note therefore that at least one mariner was impressed by its practical value. Captain Howard Roberts7 of the Anglo-Saxon Line s.s. Purpura, finding himself in a part of the world (South-east Asian waters) where the method could be tested with advantage, set out to construct a table giving 'Sum of Altitude and Hour Angle' for various values of latitude and declination. A copy of the table was sent to the Editor of the Nautical Magazine and a specimen extract was reproduced in that journal. Roberts wrote: 'I use them myself with excellent results ... and can obtain a position line in three minutes....' Goodwin, who described Captain Roberts' experiments, ${ }^{7}$ suggested that it might be worth while to compile tables similar to those by Roberts, to cover a range of latitude up to $30^{\circ}$, but these never materialized.

\section{REFERENCES}

1 Goodwin, H. B. $(1923)$. New notions in the long distance navigation of the air, Naut. Mag., $110,4^{8}$.

2 Houël, J. (1 88I ). Tables de Logarithmes a 5 decimales et Logarithmes d'addition de soustraction de Gauss, Paris.

3 Cotter, C. H. (197 I). Gaussian logarithms and navigation. This Journal, 24, 569.

4 Hughes, A. J. (1946). History of Air Narigation, London. 
5 Goodwin, H. B. (1923). The Coutinho method for zenith distance and the Ball altitude tables, Naut. Mag., 1 10, 294.

6 Ball, F. (1 907). Altitude or Position-Line Tables, London.

7 Goodwin, H. B. (1924). The Coutinho method for position lines practically tested at sea, Naut. Mag., 111 , 188.

\title{
Collision Avoidance Systems
}

\author{
J. Watt \\ (Marconi Communication Systems)
}

I was sorry to have missed the two papers by Captain K. D. Jones and Mr P. J. Houseley on the above subject, presented at a recent meeting of the Institute, and the subsequent discussion. Fortunately both Captain Jones and Mr. Houseley have been kind enough to let me see copies of their papers and I would like to add two pieces of information which may be of interest with reference to Captain Jones's paper.

The first is in regard to the making of 'the first decision' in clear weather. Captain Jones says that most mariners on sighting a target decide on the risk, or the probable miss distance, by an accurate even if intuitive evaluation of aspect and range. (They must also take into account the relative bearing of the target and its speed relative to that of own ship.) For the purposes of his argument Captain Jones omits from the clear weather case the alternative method of using radar in assessing the risk or probable miss distance. Evidence on the comparative accuracies of these two methods may be of interest; a series of demonstration runs on the Predictor automatic plotting radar in Elettra III in the English Channel provided an opportunity to obtain some such evidence.

On one occasion which I have in mind, under conditions of clear visibility in daylight, a ship estimated at about 2000 tons was seen about $45^{\circ}$ off the port bow at a (radar) range of 7 miles in a crossing situation. A consensus of five or six practising mariners, on board for the demonstration, visually inspected the ship and said that it would pass well clear ahead. Meanwhile the radar was maintaining an automatic 4-plot 6 minute track which, when switched to Relative Track mode and extrapolated by cursor, indicated a close passing ahead of within one quarter mile, i.e. within 0.15 inch on the CRT screen. The consensus declared that the miss distance would be much greater and that the radar was wrong. So the situation was allowed to develop. The extrapolated 4-plot relative track stuck consistently to its indication of a miss distance of something under a quarter of a mile ahead, and in due course the target crossed our bows at about two cables distance.

The visual assessment at 7 miles range was made using unaided human eyesight and human judgment, to work out a problem in space and time to which eyesight and judgment are not very well suited. The radar on the other hand in presenting a compass stabilized plot of the relative motion of the target, which required for its accuracy no knowledge of the target's aspect nor any assumptions concerning the speed of either vessel, and which only needed to be extrapolated to show the bearing and distance of CPA, was doing the job it does best. 